hindrance is increased, either in the ketone or the reducing alcohol, there is an increase in the proportion of cis isomer in the mixture of alcohols produced (for example, 2-methylcyclohexanone gives 50 per cent cis, whereas menthone gives 70 per cent cis). Construction of models of the postulated transition state shows that this trend should be observed in such reductions.

Any mechanism for the Meerwein--Ponndorf reduction should account for its specific nature and the excellent yields obtainable, and free-radical mechanisms such as that proposed by Hodgson ${ }^{6}$ are less satisfactory from this point of view.

It is probable that if experimental conditions are chosen to suppress competing side-reactions (Tischtschenko reaction, aldol condensation), and if the product does not undergo further reaction (dehydra. tion or rearrangement), the yields in this reaction will be practically quantitative. One way of greatly improving the yields, particularly from aldehydes and highly reactive ketones, is to add the carbonyl compound slowly during the reaction, so that its concentration in the mixture is always very low. An example of the value of this modification is the reduction of benzalacetone, which gives styryl methyl carbinol in 95 per cent yield.

We wish to acknowledge financial assistance from the Commonwealth Research Fund.

L. M. JACKMAN

JohN A. MiLts

Johnson Chemical Laboratories,

University of Adelaide. May 25.

${ }^{1}$ Meerwein, et al., J. prakt. Chem., 147, 24 (1936).

"Hammett, "Physical Organic Chemistry", 352 (McGraw-Hill Book Co., New York, 1940).

"Woodward, Wendler and Bratschy, J. Amer. Chem. Soc., 67, 1425 (1945).

- Doering, Cortes and Knox, J. Amer. Chem. Soc, 69, 1700 (1947).

${ }^{8}$ Read and Walker, $J$. Chem. Soc., 308 (1934).

- Davies and Hodgson, J. Soc. Chem. Indust., 62, $109 T$ (1943).

\section{State of Manganese in Manganese Oxides}

CHEMICAL estimation of trivalent manganese has been possible using a stable complex ion formed with acetylacetone. This complex is formed from solutions of red manganic sulphate and also when $\gamma-\mathrm{Mn}_{2} \mathrm{O}_{3}$ is dissolved in concentrated hydrochloric acid in the presence of acetylacetone.

When manganese dioxide is dissolved in hydrochloric acid in the presence of acetylacetone, only one equivalent of chlorine is liberated in place of the normal value of two equivalents. It is thought that in the presence of excess acetylacetone, the manganese tetrachloride $\left(\mathrm{MnCl}_{4}\right)$ reacts to form the stable trivalent complex ion, the chlorine liberated chlorinating the acetylacetone rapidly.

In the presence of 0.5 normal potassium iodide and normal hydrochloric acid, the chlorinated acetylacetone reacts quantitatively to liberate one equiv. alent of iodine. Thus it is possible, using acotylacetone, to estimate manganese tetrachloride in the presence of manganese trichloride, and the sum of the concentrations of the two chlorides can be estimated separately in the absence of acetylacetone.

Using acetylacetone, the following oxides have been analysed and have reacted as the ion mixtures tabulated below.

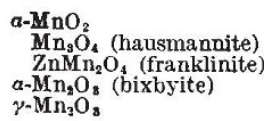

Forms of manganese dioxide after solution in hydrochloric acid react chiefly as tetravalent ions. However, oxygen-deficient types as described by Cole, Wadsley and Walkley ${ }^{1}$ give rise to a certain quantity of trivalent ions. The reaction of $\mathrm{Mn}_{3} \mathrm{O}_{4}$ is in agreement with the structure proposed by Verwey

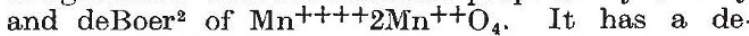
formed spinel structure with sixteen cations in octa hedral positions and eight in tetrahedral positions. From radius-ratio considerations it appears that the cation of manganese most suitable to occupy the tetrahedral positions is the tetravalent ion with a radius of about $0.52 \mathrm{~A}$. Franklinite, which also has a spinel structure, reacts as would be expected from the analogy with $\mathrm{Mn}_{3} \mathrm{O}_{4}$.

The $\gamma$-form of manganic oxide $\left(\mathrm{Mn}_{2} \mathrm{O}_{3}\right)$ on solution in hydrochloric acid reacts entirely as trivalent ions. This is in agreement with the proposal of Verwey and deBoer ${ }^{2}$. The reaction of $\alpha-\mathrm{Mn}_{2} \mathrm{O}_{3}$ is anomalous. This oxide has the $C$-type oxide structure typical of certain rare earth oxides. From present evidence it is difficult to decide if all the cations are strictly equivalent. However, all the atoms are in six co-ordination, and it seems unlikely that the tetravalent manganese ion could occupy these positions, due to its small size. Zachariasen $^{3}$ considers all these oxides to contain trivalent ions.

Reaction between $\mathrm{Mn}^{++}$and $\mathrm{Mn}^{++++}$to produce $\mathrm{Mn}^{+++}$as described by Cowley and Walkley ${ }^{4}$ does not seem to occur in the presence of acetylacetone, probably due to the removal of a chlorine atom from the manganese tetrachloride and its addition to the acetylacetone.

A complete study of the reaction of all manganese oxides, the kineties of the reaction and the nature of the complex ions will be published elsewhere.

\section{Chemistry Department, University of Otago, New Zealand.} June 3.

${ }^{1}$ Cole, W. F., Wadsley, A. D., and Walkley, A., preprint $92-2$, Elect. Chem. Soc. (1947)'

${ }^{2}$ Verwey, E. J. W., and deBoer, J. H., Rec. trav. chim., 55, 531 (1936). - Zachariasen, W., Chem. Abst., 23, 1790.

- Cowley, J. M., and Walkley, A., Nature, 161, 173 (1948).

\section{Effect of Adrenal Cortical Steroids upon the Formation of Carbohydrate by Rat Liver Slices}

SECKEL ${ }^{1}$ showed that addition of eschatine (adrenal cortical extract) to rat liver slices incubated aerobically in phosphate-Ringer solution caused inhibition of glycogenolysis. This was confirmed by Chiu and Needham ${ }^{2}$, who found, further, that this inhibition is absent if incubation takes place in an atmosphere of nitrogen. They therefore suggested that the effect of the hormone is on glycogen synthesis, the degree of glycogenolysis observed being the resultant of simultaneous breakdown and synthesis. Deane et al. ${ }^{3}$ have, indeed, shown histologically that, under similar conditions to ours, glycogen disappearance may occur in one part of a liver slice while formation is occurring in another part. When the effect of the hormone was tested under conditions favourable to synthesis of glycogen, that is, in the presence of substrates such as pyruvate, lactate, glutamate, an increased synthesis was observed over that in the control without hormone. 